\title{
Quantitative Ion Beam Analysis for Light Elements using In-air and High Depth Resolution Systems
}

\author{
Kohtaku Suzuki $^{1 *}$, Ryoya Ishigami ${ }^{1}$, Kazufumi Yasunaga ${ }^{1}$, Keisuke Yasuda ${ }^{2}$ \\ 1 The Wakasa Wan Energy Research Center, 64-52-1 Nagatani, Tsuruga, Fukui, 914-0192 Japan \\ 2 Kyoto Prefectural University, 1-5 Shimogamohanki-cho, Sakyo-ku, Kyoto, Kyoto, 606-8522 Japan \\ * Corresponding author: e-mail: ksuzuki@werc.or.jp
}

\begin{abstract}
Ion beam is used for quantitative element analysis. In the Wakasa Wan Energy Research Center (WERC), various types of ion beam analysis; Particle Induced X-ray Emission (PIXE), Rutherford Backscattering Spectrometry (RBS), and Elastic Recoil Detection Analysis (ERDA), have been performed with a 5 MV tandem accelerator. Recently, in-air and time-of-flight systems have been developed in WERC. The in-air measurement is required often for hydrogen storage materials to determine hydrogen quantity. Hydrogen quantities of magnesium-hydride $\left(\mathrm{MgH}_{x}\right)$ thin films after production and after hydrogen absorption by magnetron sputtering were measured by the in-air system. The time-of-flight (TOF) ERDA measurement is useful for multi element simultaneous analysis with high depth resolution. $\mathrm{The}^{\mathrm{TiO}_{2}}$ thin film of $10 \mathrm{~nm}$ thickness has been measured with the TOF ERDA system.
\end{abstract}

Key words: Ion beam analysis, PIXE, RBS, ERDA, In-air, TOF

\section{INTRODUCTION}

The ion beam analysis (IBA) is a powerful tool for quantitative elemental measurements on surface regions without destructive. Applicable range of IBA covers basically all elements and isotopes. PIXE can be performed simultaneous measurement of multi elements with ppm order. RBS and ERDA can measure quantity and depth distribution of middle to heavy elements, and light elements, respectively. The other IBA methods; nuclear reaction analysis (NRA), can analyze to focus one element. These analysis usually use several to several tens of $\mathrm{MeV}$ ion beams.

Many experiments and developments for various research fields have been performed using an accelerator system in WERC. Over review will be reported in the reference [1]. Examples of IBA which have been done in WERC will introduce on this report. The target range of IBA is very wide; various materials, living and plant bodies, thin films, andmaterials. Various analysis have been performed using above methods. Furthermore, in-air and time-of-flight systems have been developed in WERC.

\section{ACCELERATORS AND BEAM LINES OF WERC}

The accelerator system with a $5 \mathrm{MV}$ tandem accelerator and a $200 \mathrm{MeV}$ proton synchrotron (Multi-purpose Accelerator with Synchrotron and Tandem) was constructed in WERC [2]. The tandem is used for the main accelerator to IBA experiments. Handled ion sources are $\mathrm{H}, \mathrm{He}, \mathrm{C}, \mathrm{N}, \mathrm{O}, \mathrm{Si}, \mathrm{Ni}$, and $\mathrm{Cu}$, until now. Maximum acceleration energies of these sources with the tandem are $10 \mathrm{MeV}$ for $\mathrm{H}, 15 \mathrm{MeV}$ for $\mathrm{He}, 25 \mathrm{MeV}$ for the other ions, respectively.

The 5 beam lines have been installed for beams from the tandem, which are the parallel beam, the $\mu$-beam, ion analysis, the $\mu$-beam in the air, and the ion irradiation lines The parallel beam line has long distance double slits to provide parallel beam. Beam lines named $\mu$-beam can control beam size with $\mu \mathrm{m}$ order. This line has been mainly used for RBS and the ion channeling. The $\mu$-beam line has an X-Y slit, an aperture slit, a Q-magnet to focus beam down to a few $\mu \mathrm{m}$ size, and also $\mathrm{X} / \mathrm{Y}$ electrodes for scanning beam. This line has been used for $2 \mathrm{~d}$ mapping of PIXE/NRA and pinpointed small area RBS/ERDA. The ion analysis line has a large chamber, and can be performed RBS, ERDA, and time-of-flight systems. The $\mu$-beam in the air line is vertical beam course for liquid materials and cells with PIXE. This beam line takes beam into air through a thin polyimide film. The ion irradiation line has high and low temperature target stages. This line can be utilized for RBS and ERDA experiments.

\section{IN-AIR ANALYSIS}

IBA is basically performed in the vacuum, because beam energy is often used for several $\mathrm{MeV}$ regions. However, some samples, such as hydrogen storage materials, desorb hydrogen in the vacuum. In particular, hydrogen around the surface region may decrease dramatically. This means that IBA has an uncertainty to determine hydrogen quantity.

\subsection{Hydrogen and deuteron measurement in-air}

ERDA experiments in-air were performed for titanium -hydrides $\left(\mathrm{TiH}_{x}\right)$ and -deuterides $\left(\mathrm{TiD}_{x}\right)$ on the ion irradiation line at WERC [3]. The $15 \mathrm{MeV}$ He was used for beam. The beam exit window was a $5 \mu \mathrm{m}$ Mo foil, and targets were set $10 \mathrm{~mm}$ behind of the window. An ERDA detector was set at atmospheric pressure. On this setup, the depth resolution became $0.74 \mu \mathrm{m}$ on the surface, and hydrogen/deuteron (H/D) distributions were measured up to $8 \mu \mathrm{m}$ from the surface. Atomic ratios of $\mathrm{TiH}_{x}$ and $\mathrm{TiD}_{x}$ were determined, however nuclear reactions effected to the determination. And also the resolution of the ERDA detector became worse gradually since it was set at the atmospheric pressure. 
3.2 In-air ERDA system at the $\mu$-beam line

New in-air ERDA system was developed on the $\mu$-beam line at WERC [4]. This system uses a $200 \mathrm{~nm}$ thick silicon-nitride ( $\mathrm{Si}-\mathrm{N}$ ) window for the beam port. He beam passes through the window, and is irradiated to targets a few $\mathrm{mm}$ behind of the window. Scattered $\mathrm{H}$ goes to vacuum via the same window and is detected by an ERDA detector in the vacuum. The beam energy can be selected to several $\mathrm{MeV}$ because the energy loss is small for the very thin Si-N window. This setup improves suppressions of nuclear reaction effects and detector deteriorations.

3.3 Hydrogen analysis of hydrogen storage materials in-air Hydrogen storage materials (magnesium-hydride: $\mathrm{MgH}_{x}$ ) which were prepared by magnetron sputtering were measured using the new in-air ERDA system. Titanium (Ti) substrates were used for the sputtering, and nickel (Ni) was covered for a catalyst. Thicknesses of Ni and $\mathrm{MgH}_{x}$ were $50 \mathrm{~nm}$ and $500 \mathrm{~nm}$, respectively. The $\mathrm{Ni} / \mathrm{MgH}_{x} / \mathrm{Ti}$ samples are shown in Fig. 1.

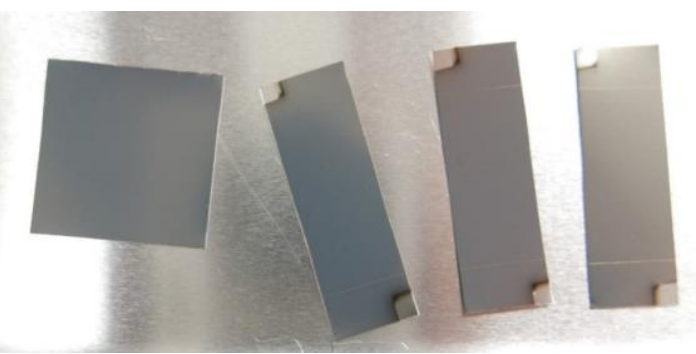

Fig. 1. Magnesium-hydrides $\left(\mathrm{Ni} / \mathrm{MgH}_{x} / \mathrm{Ti}\right)$ which were created by magnetron sputtering.

$\mathrm{H}$ quantities of $\mathrm{Ni} / \mathrm{MgH}_{x} / \mathrm{Ti}$ and high molecule samples were measured with the in-air system. Measured samples are as follows:

(a) $\mathrm{Ni} / \mathrm{MgH}_{x} / \mathrm{Ti}$ keeping in $\mathrm{H}$ gas of the atmospheric pressure after production,

(b) $\mathrm{Ni} / \mathrm{MgH}_{x} / \mathrm{Ti}$ after heated up to 200 degree to absorb hydrogen,

(c) Ti plate for the background subtraction,

(d) Polyphenylene sulfide film (PPS) of $1.2 \mu \mathrm{m}$ thickness,

(e) Polyethylene terephthalate film (PET) of $100 \mu \mathrm{m}$ thickness.

The 5.1 MeV He${ }^{2+}$ beam was used for in-air measurements of these samples. Total amounts of irradiated beam were 100-500 nC for each target. $\mathrm{H}$ amounts were stable between these measurements ( $\mathrm{H}$ stabilities were shown in ref. [4-5]). $\mathrm{H}$ distributions can be measured up to approximately $3 \mu \mathrm{m}$ from the surface on this energy.

$\mathrm{H}$ energy distributions of (a)-(e) samples are shown in Fig. 2. All spectra rise up around 1600 channel. This region corresponds to surface of these samples. $\mathrm{H}$ can be measured up to $3 \mu \mathrm{m}$ from the surface for the $5.1 \mathrm{MeV}$ $\mathrm{He}^{2+}$ beam. The (a)-(d) samples can be measured all region (surface to interface) of films. The 1000-1200 channel region corresponds to interface/reverse side of these (a)-(d) samples. If the energy (depth) resolution was very high, the spectra shape of thin films became trapezoid (rapidly rising up/falling down $\mathrm{Y}$ axis counts at surface/interface, and flat intervening region). However, the depth resolution of the in-air measurement is about $300 \mathrm{~nm}$, spectra shapes (a)-(d) are similar to the gauss function. On the other hand, the shape of the spectrum (e) is similar to trapezoid. The $1400-1600$ channel region corresponds to the PET surface. The $\mathrm{Y}$ axis counts gradually decrease in the 200-1300 channel region. This region corresponds to inside of PET up to $3 \mu \mathrm{m}$ from the surface. $\mathrm{H}$ is distributed uniformly in the region, however the detected $\mathrm{H}$ is gradually decrease because of the $\mathrm{H}-\mathrm{He}$ cross-section and the stopping power changes. The detection threshold is set in the region less than 200 channel, therefore $\mathrm{H}$ cannot be detected in the deeper region.

The PPS has features of high irradiation resistance, high temperature resistance, low hygroscopic, and also is manufactured very thin films. For these reasons, the PPS can be used as a comparison material of $\mathrm{H}$ analysis. The $\mathrm{H}$ surface density of the PPS film is $3.6 \times 10^{18}$ atoms $/ \mathrm{cm}^{2}$. H counts are summed up 500-2000 channel, then H quantity ratios between the PPS and (a)-(c) samples become $71.1 \pm 1.3 \%, 18.2 \pm 0.4 \%$, and $5.4 \pm 0.2 \%$, respectively. After background subtraction, $\mathrm{H}$ quantity ratios of (a) and (b) are $65.7 \%$ and $12.8 \%$. This means that the absorbed $\mathrm{H}$ of about $20 \%$ in amount is left after the sample is heated.

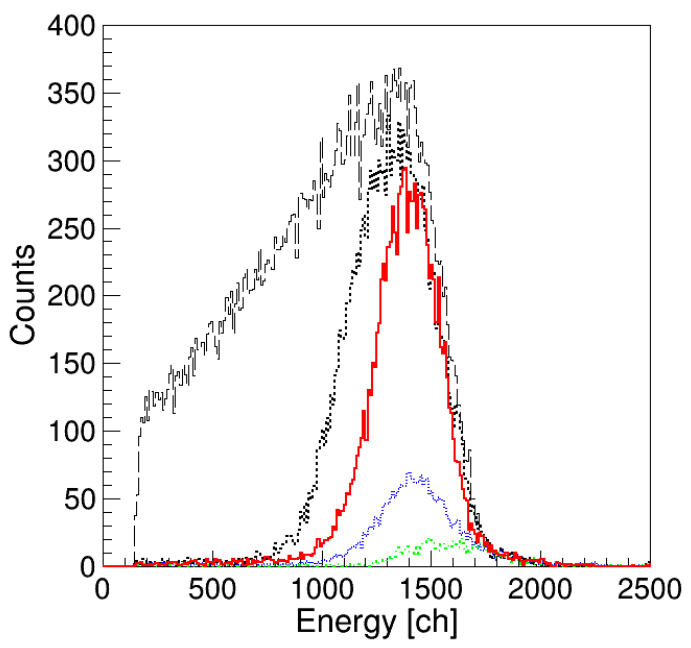

Fig. 2. H energy spectra of in-air measurements. The long dashed (black), the dashed (black), the continuous (red), the dotted (blue), the dash-dotted (green) lines correspond to (a)-(e) samples.

3.4 The other in-air experiments

Some ceramics, such as lithium-zirconate, lithium-silicate, absorb water vapor and carbon dioxide in the air. There weights increase several to several tens of weight \%. However absorption conditions depend on manufacturing conditions. To determined absorbed $\mathrm{H}$ quantity, these ceramics have been measured by the in-air system [5]. 


\section{TIME-OF-FLIGHT ANALYSIS}

Conventional IBA methods; RBS and ERDA, measure only energies of scattered/recoiled elements. The time-of-flight (TOF) method measure TOF (velocity) and energy of elements. Therefore, it can determine the mass of an element using the energy and velocity information. And also, TOF system do not have a stopper foil, thus the element energy can be determined with a high resolution. This method is suitable for precise depth analysis and very thin film analysis.

\subsection{Prototype TOF-ERDA system}

A TOF system was developed on the ion analysis line in WERC [6]. This system consists a silicon surface-barrier (SSB) and a transmission detectors which is set at 40 degree from the beam line. Thus this method is called TOF-ERDA. The SSB detector measures element energies. The transmission detector is constructed by a carbon thin foil, a multi-channel plate (MCP) detector, and electric mirrors. An element passes through the carbon foil, second electrons are generated, and the MCP detects these second electrons which guided by electric mirrors. The TOF is determined by time information of the transmission and the energy detectors. The surface depth resolution reaches $6.0 \mathrm{~nm}$ with the $3.5 \mathrm{MeV}$ He beam [7]

\subsection{Upgrade TOF-ERDA system}

Prototype system uses a SSB and a transmission detectors to determine the TOF. The depth resolution are mainly corresponded to the SSB time resolution. An upgrade TOF-ERDA system consists a SSB and two transmission detectors [8]. The TOF is measured by two transmission detectors, and the time resolution becomes 390 picosecond. The depth resolution achieves $1.3 \mathrm{~nm}$ for $2.0 \mathrm{MeV}$ He beam. The detection limit of the areal density for oxygen reaches $3.8 \times 10^{14} \mathrm{~cm}^{-2}$.

4.3 Thin film analysis using the upgrade system

Appropriate ion species should be selected for beam according to target elements. When light element beam; such as $\mathrm{He}$, is used, only light elements can be measured. When a beam heavier than $\mathrm{He}$ is used, measurable elements (lighter than Ar) become wide. However, He beam is suitable for $\mathrm{H}$ and $\mathrm{Li}$ analysis.

A titanium-oxide $\left(\mathrm{TiO}_{2}\right)$ thin film of $10 \mathrm{~nm}$ thickness deposited on $\mathrm{Si}$ wafer was measured by the upgrade system with $3.5 \mathrm{MeV}$ He and $\mathrm{C}$ beam. Fig. 3 shows two dimensional histograms of TOF versus energy for the $\mathrm{TiO}_{2}$ thin film. Loci corresponding to $\mathrm{He}, \mathrm{C}, \mathrm{O}, \mathrm{Si}$, and $\mathrm{Ti}$ were clearly observed. Ti cannot be observed with $\mathrm{He}$ beam, because the momentum transfer of $\mathrm{Ti}$ from $\mathrm{He}$ beam is very small.

Event selections were performed on the two dimensional histogram of $\mathrm{C}$ beam. Events of each loci were selected, and selected data were projected to the TOF axis. The TOF spectrum of $\mathrm{O}$ events is shown in Fig. 4. Surface and interface events are distributed around 2420, and 2380 channels, respectively. The peak width corresponds to the thickness of the $\mathrm{TiO}_{2}$ thin film $(10 \mathrm{~nm})$. The surface resolution is determined as $2.0 \mathrm{~nm}$ by the fitting with frequency functions.
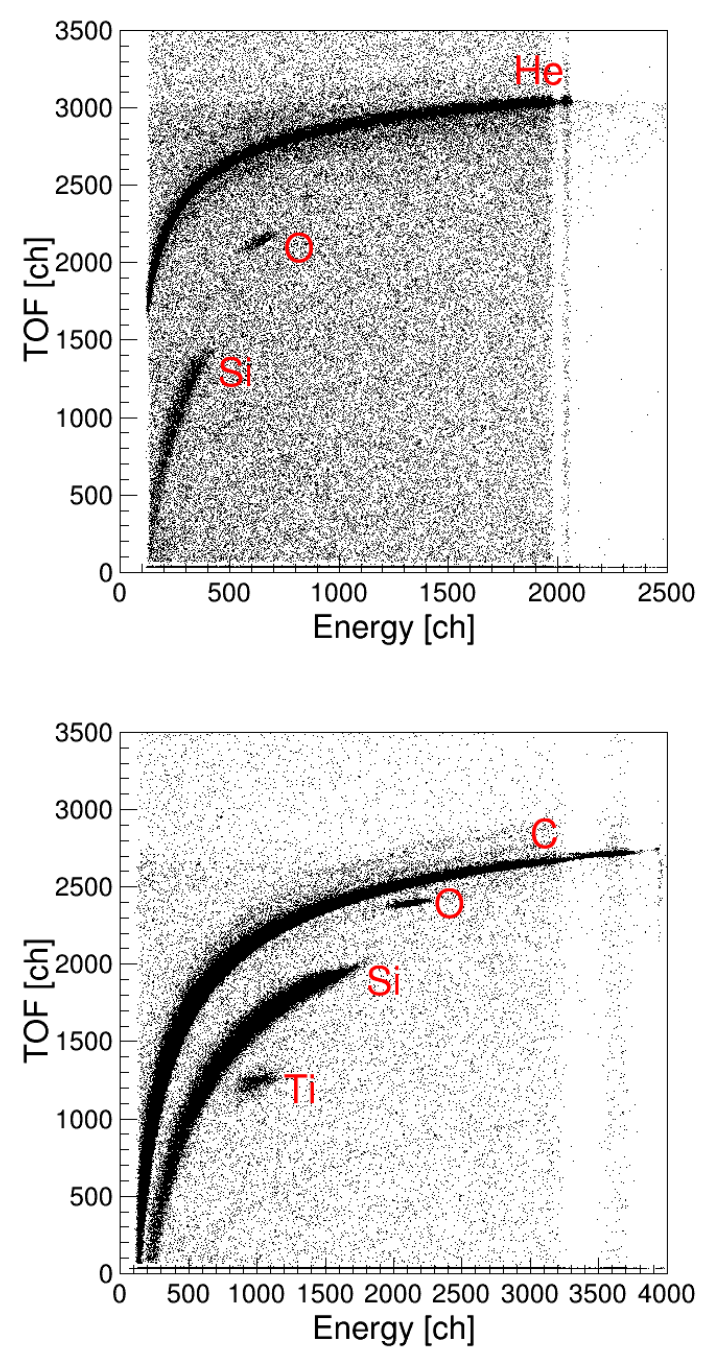

Fig. 3. Two dimensional histograms of TOF vs energy for the $\mathrm{TiO}_{2}$ thin film. Beam is used for $\mathrm{He}$ (the upper histogram) and C (the lower histogram).

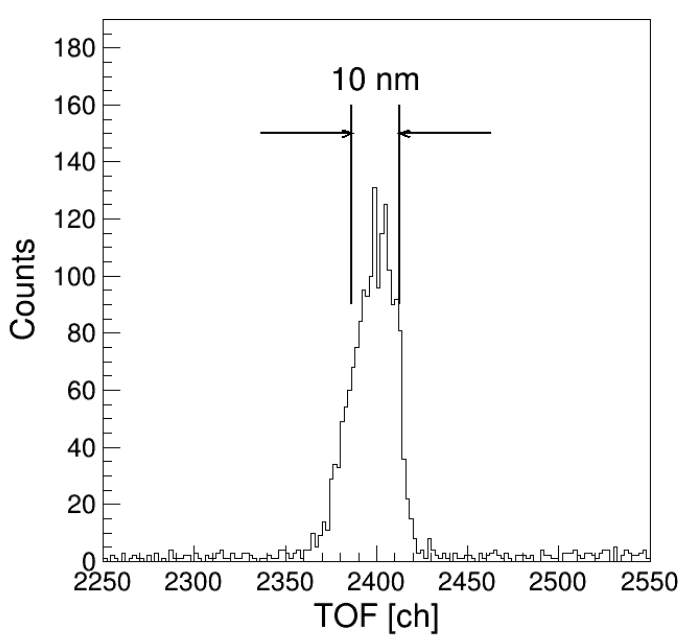

Fig. 4. TOF spectrum of $\mathrm{O}$ events. The peak width corresponds to the thickness of the $\mathrm{TiO}_{2}$ thin film $(10 \mathrm{~nm})$. 
4.4 Developments of TOF-ERDA techniques

TOF-ERDA method has affinity for light element analysis, such as $\mathrm{H}, \mathrm{Li}$, and so on. Therefore, high depth resolution analysis using TOF-ERDA is suitable for diamond-like carbon thin films and all solid-state lithium-ion batteries. A lithium-ion battery was measured by the TOF-ERDA system, and depth distributions of light elements were observed [9]. And also, the efficiency of transmission detectors of the TOF-ERDA system was obtained.

RBS and ERDA methods are often performed within Rutherford scattering energy regions. However, beam energies should be selected to film thickness or measurable depth information. When high energy beam is used, the cross section deviates from Rutherford scattering. Cross sections of $\mathrm{He}_{-}{ }^{14} \mathrm{~N}$ and $\mathrm{He}-{ }^{7} \mathrm{Li}$ were observed for TOF-ERDA measurements [10-11].

\section{THE OTHER IBA}

Conventional IBA methods, such as PIXE, RBS, ERDA, and NRA, have been performed at WERC. Experiments with these methods are introduced in this section.

\subsection{PIXE measurements}

PIXE measurements have been performed mainly at the $\mu$-beam line in WERC. This line can measure 2-dimensional mapping with X-Y scanning electrodes, and the position resolution becomes several $\mu \mathrm{m}$ [12].

The aluminum ( $\mathrm{Al})$ is well known that its ionic form is toxic to all plants. However, tea plants require $\mathrm{Al}$ for its growth, and $\mathrm{Al}$ is accumulated in tea plants. This means that tea plants have some mechanisms of detoxification. Tea leaves were measured by $\mu$-beam PIXE at WERC [13-15]. Many elements ( $\mathrm{Al}, \mathrm{Si}, \mathrm{P}, \mathrm{S}, \mathrm{K}, \mathrm{Ca}$, etc.) is observed simultaneously. $\mathrm{Al}$ is distributed in epidermal cells, and silicon $(\mathrm{Si})$ distribution is correlated to the $\mathrm{Al}$ distribution.

Some targets, such as living body, require keeping moisture. These targets cannot be installed to the vacuum. An in-air method of $\mu$-beam PIXE was developed for tooth measurements [16-19]. The uptake of fluoride (F) effects the increasing of acid resistance for teeth. F-containing materials, such as toothpaste, are valid to the carious inhabitation. However, there is no suitable analysis methods of F distributions within teeth. Measurements of the particle induced $\gamma$-ray emission (PIGE) which is a kind of NRA is performed for $\mathrm{F}$ analysis of teeth. The reaction of ${ }^{19} \mathrm{~F}(\mathrm{p}, \alpha \gamma){ }^{16} \mathrm{O}$ is used, and $\gamma$-rays are observed by a bismuth-germanate $\left(\mathrm{Bi}_{4} \mathrm{Ge}_{3} \mathrm{O}_{12} ; \quad \mathrm{BGO}\right)$ scintillation detector. Since the main material of teeth is calcium $(\mathrm{Ca})$, Simultaneous $\mathrm{F}$ and $\mathrm{Ca}$ analysis by PIXE and PIGE has been performed for teeth [20-21]. The relation between tooth-bound $\mathrm{F}$ and F-containing materials has been studied.

\subsection{ERDA measurements}

ERDA is one of the method for the quantitative $\mathrm{H}$ analysis. The diamond-like carbon (DLC) gives various features, such as high hardness, low coefficient of friction, corrosion resistance, and so on, to materials. These properties changes typically the ratio of diamond bonding $\left(\mathrm{sp}^{3}\right)$, graphite bonding $\left(\mathrm{sp}^{2}\right)$, and $\mathrm{H}$ content. There are many methods for DLC manufacturing, however the $\mathrm{H}$ amount cannot be determined without $\mathrm{H}$ analysis. ERDA is often used for the $\mathrm{H}$ analysis in DLCs. The correlation between the $\mathrm{H}$ intensity by glow discharge optical emission spectrometry (GD-OES) and the $\mathrm{H}$ content by ERDA was measured [22].

Lithium ( $\mathrm{Li}$ ) is also difficult elements for quantitative analysis. Recently, $\mathrm{Li}$-ion batteries is indispensable for our life, and developments of all-solid type Li-ion batteries have been performed actively in the world. All-solid batteries have possibilities of high safety, low cost, and high performances. Thin film Li-ion batteries of which thickness is about $2 \mu \mathrm{m}$ is measured by the transmission ERDA method [23]. The difference of Li distribution was observed between charge and discharge to batteries.

\subsection{NRA measurements}

Carbon (C) is one of main elements for materials. However, it sometimes difficult to analyze by RBS/ERDA/PIXE. Many materials include heavier and lighter elements than $\mathrm{C}$, thus the separation of $\mathrm{C}$ and the other elements is difficult. And also, the X-ray energy from $\mathrm{C}$ is too low to detect with $\mathrm{X}$-ray detector. NRA can concentrate to measure one element. An analytical method was developed using the ${ }^{12} \mathrm{C}(\mathrm{p}, \mathrm{p}$ ' $\gamma)$ reaction at WERC [24-25]. The cross-section of this reaction is large, and it is easy to measure $\gamma$-rays because of the high $\gamma$-ray energy (4438 keV).

\section{SUMMARY}

Many IBA experiments have been performed with the 5 MV tandem accelerator at WERC. Our beam lines adapt to various type of IBA methods; 2-dimentional analysis of PIXE/PIGE, light elements analysis of ERDA, NRA, and in-air analysis. Object targets are also adapted to very wide, such as plants, living body, DLC, Li-ion battery, semiconductors, etc. Systems of TOF-ERDA and in-air ERDA has been developed for multi elements analysis and in-air analysis. These system are very unique in the world. Thin film analysis of $\mathrm{nm}$ scale can be done with high depth resolution by TOF-ERDA. Quantitative hydrogen analysis in-air is suitable for hydrogen storage materials.

\section{ACKNOWLEDGMENTS}

The authors thank the staff at WERC for supporting. A part of this work was supported by JSPS KAKENHI Grant Number JP18K04948.

\section{REFERENCES}

[1] A. Iwase, S. Hatori, T. Kurita, K. Kume, M. Maeda, K. Takagi, M. Hatashita, R. Ishigami, K. Suzuki, Trans. Mat. Res. Soc. Japan to be published.

[2] S. Hatori, T. Kurita, Y. Hayashi, M. Yamada, H. Yamada, J. Mori, H. Hamachi, S. Kimura, T. Shimoda, M. Hiroto, T. Hashimoto, M. Shimada, H. Yamamoto, N. Ohtani, K. Yasuda, R. Ishigami, M. Sasase, Y. Ito, M. Hatashita, K. Takagi, K. Kume, S. Fukuda, N. Yokohama, G. Kagiya, S. Fukumoto, M. Kondo, Nucl. Inst. Meth. B, 241, 862-869 (2005).

[3] R. Ishigami, Y. Ito, K. Yausda, S. Hatori, Nucl. Inst. Meth. B, 241, 423-427 (2005).

[4] K. Suzuki, Y. Nakata, Nucl. Inst. Meth. B, 450, 135-138 (2019).

[5] K. Suzuki, B. Tsuchiya, K. Yasuda, Y. Nakata, Nucl. Inst. Meth. B, 478, 169-173 (2020).

[6] K. Yasuda, C. Batchuluun, R. Ishigami, S. Hibi, Nucl. 
Inst. Meth. B, 268, 2023-2027 (2010).

[7] K. Yasuda, C. Batchuluun, R. Ishigami, S. Hibi, Nucl. Inst. Meth. B, 269, 1019-1022 (2011).

[8] K. Yasuda, Y. Kajitori, M. Oishi, H. Nakamura, Y. Haruyama, M. Saito, K. Suzuki, R. Ishigami, S. Hibi, Nucl. Inst. Meth. B, 442, 53-58 (2019).

[9] Y. Saito, M. Fujita, Y. Aoki, M. Yoshikawa, K. Yasuda, R. Ishigami, Y. Nakata, Nucl. Inst. Meth. B, 371, 273-277 (2016).

[10] K. Yasuda, H. Tsuchida, T. Majima, Nucl. Inst. Meth. $B, 343,1-4$ (2015).

[11] K. Suzuki, K. Yasuda, R. Ishigami, Y. Yasunaga, Nucl. Inst. Meth. B to be published.

[12] K. Yasuda, M. Hatashita, S. Hatori, T. Inomata, R. Ishigami, Y. Ito, T. Kurita, M. Sasase, K. Takagi, Nucl. Inst. Meth. B, 210, 27-32 (2003).

[13] K. Takahashi, S. Uemori, H. Yamashita, M. Saito, Y. Haruyama, K. Yasuda, Int. Jour. of PIXE, 22, Nos 1\&2, 225-230 (2012).

[14] S. Uemori, H. Yamashita, M. Saito, Y. Haruyama, K. Yasuda, Int. Jour. of PIXE, 23, Nos 1\&2, 13-19 (2012).

[15] Y. Haruyama, T. Fujiwara, K. Yasuda, M. Saito, K. Suzuki, Quantum Beam Sci., 3, 9 (2019).

[16] K. Yasuda, Y. Ito, R. Ishigami, K. Takagi, M. Hatashita, S. Hatori, Int. Jour. of PIXE, 10, Nos 3\&4, 97-100 (2000).

[17] H. Yamamoto, Y. Iwai, S. Ebisu, M. Nomachi, K. Yasuda, T. Sakai, T. Kamiya, Int. Jour. of PIXE, 19, Nos 1\&2, 91-102 (2009).

[18] K. Yasuda, M. Nomachi, Y. Sugaya, H. Yamamoto, K. Komatsu, Nucl. Inst. Meth. B, 269, 2180-2183 (2011).

[19] K. Yasuda, Int. Jour. of PIXE, 25, Nos 1\&2, 225-231 (2015).

[20] H. Yamamoto, Y. Iwai, S. Ebisu, H. Komatsu, M. Nomachi, Y. Sugaya, K. Yasuda, Int. Jour. of PIXE, 21, Nos 1\&2, 31-38 (2011).

[21] K. Okuyama, Y. Tamaki, H. Yamamoto, K. Yagi, M. Hayashi, Y. Matsuda, T. Saito, K. Yasuda, K. Suzuki, Int. Jour. of PIXE, 27, Nos 1\&2, 1-9 (2011).

[22] H. Takahara, R. Ishigami, K. Kodama, A. Kojo, T. Nakamura, Y. Oka, J. Anal. At. Spectrom., 31, 940-947 (2016).

[23] K. Morita, B. Tsuchiya, J. Ohnishi, T. Yamamoto, Y. Iriyama, H. Tsuchida, T. Majima, K. Suzuki, Nucl. Inst. Meth. B, 426, 30-33 (2018).

[24] K. Yasuda, S. Hatori, T. Inomata, R. Ishigami, Y. Ito, M. Sasase, Nucl. Inst. Meth. B, 219-220, 425-429 (2004).

[25] K. Yasuda, M. Sasase, R. Ishigami, Y. Ito, Nucl. Inst. Meth. B, 266, 1416-1420 (2008).

(Received April 1, 2020; Accepted May 21, 2020;

Published Online August 1, 2020) 